BIBLIOGRAPHY

Bartels, E. C., and Cattell, R. D. (1950). Ann. Surg., 131, 903. Biskind, G. R., Meyer, M. A., and Beadner, S. A. (1941). J. clin. Endocrinol. 1, 113.

British Medical Journal (1949). 1, 1131

Cole, Leslie (1950). Brit. Heart J.. 12, 232.

Goldenberg, M., Snyder, C. H., and Aranow, H. (1947). J. Amer. med. Ass., 135, 971 .

Haimovici, H. (1948). Proc. Soc. exp. Biol., N.Y., 68, 40.

MacKeith, R. (1944). Brit. Heart J., 6, 1

Reid, T. M., and Salm, R. (1949). 'British Medical Journal, 1, 1116

Spear, H. C., and Griswold, D. (1948). New Engl. J. Med., 239,

\section{A CASE OF ADRENAL PHAEOCHROMOCYTOMA}

BY

\section{J. F. PANTRIDGE, M.C., M.D., M.R.C.P. AND}

\section{McC. BURROWS, M.B. \\ (From the Belfast City Hospital)}

The first case of chromaffin tumour of the adrenal medulla correctly diagnosed and successfully removed was reported by Shipley (1929). Between 1929 and 1947 these tumours have been successfully removed in some 44 cases (Hatch et al., 1949). The object of this communication is to record the occurrence of a phaeochromocytoma with somewhat unusual features and its successful removal.

\section{Case Report}

The patient, a widow aged 66 , had suffered irregularly from "peculiar attacks" for at least seven years. Each attack began with epigastric discomfort associated with eructation of gas and sometimes with retching. These symptoms were quickly followed by a feeling like an electric shock in the limbs, back of the neck, and back of the head. The patient felt warm during the attacks, although she had noted that her hands became blue. The attacks occurred in episodes, each lasting two to four months There had been long free periods, the longest being nearly two years. During an episode there were four to seven attacks each week. For the past two years the attacks had been associated with "very rapid beating of the heart."

On examination the patient was found to be intelligent and co-operative. There was no cyanosis, oedema, or apparent rise in the jugular venous pressure. The pulse was 84 and regular, and the blood pressure $140 / 80 \mathrm{~mm}$. $\mathrm{Hg}$. There was clinical evidence of cardiac enlargement, the apex beat being in the sixth intercostal space in the anterior axillary line. The mitral first sound was split. Examination of the respiratory system revealed nothing abnormal. The liver edge was palpable 1 in. $(2.5 \mathrm{~cm}$.) below the right costal margin. A swelling, thought to be a palpable right kidney, was found in the right hypochondrium. Examination of her nervous system revealed nothing relevant.

The patient was seen during an attack on the day after admission. She appeared very apprehensive. The face was flushed, the limbs were trembling, and the hands were cold and cyanosed. The pulse was 150 and regular, and the blood pressure $270 / 170$. Subjective symptoms lasted only 15 minutes. Within half an hour the blood pressure had fallen to $120 / 80$, and the pulse rate had returned to normal. The variations in the blood pressure, spontaneous and induced, during the patient's pre-operative stay in hospital are shown in Fig. 1.

\section{Investigations}

An electrocardiogram obtained during her first attack in hospital showed sinus tachycardia, rate 150 . The next day there was a sinus rhythm, rate 55 . The standard unipolar limb and precordial leads were regarded as normal. The basal metabolic rate was - $10 \%$, and the blood cholesterol $190 \mathrm{mg}$. per $100 \mathrm{ml}$. Radiography and fluoroscopic examination of the chest revealed moderate enlargement of the left ventricle; the lung fields were clear. An intravenous pyelogram showed good excretion on both sides, with normal calices and pelves. The right kidney appeared to lie rather low. The blood urea was $44 \mathrm{mg}$. per $100 \mathrm{ml}$.; W.R. negative; fasting blood sugar was $91 \mathrm{mg}$. per $100 \mathrm{ml}$., $105 \mathrm{mg}$. during an attack.

Injection of histamine, $0.05 \mathrm{mg}$., caused a rise in blood pressure, but did not produce tachycardia or any

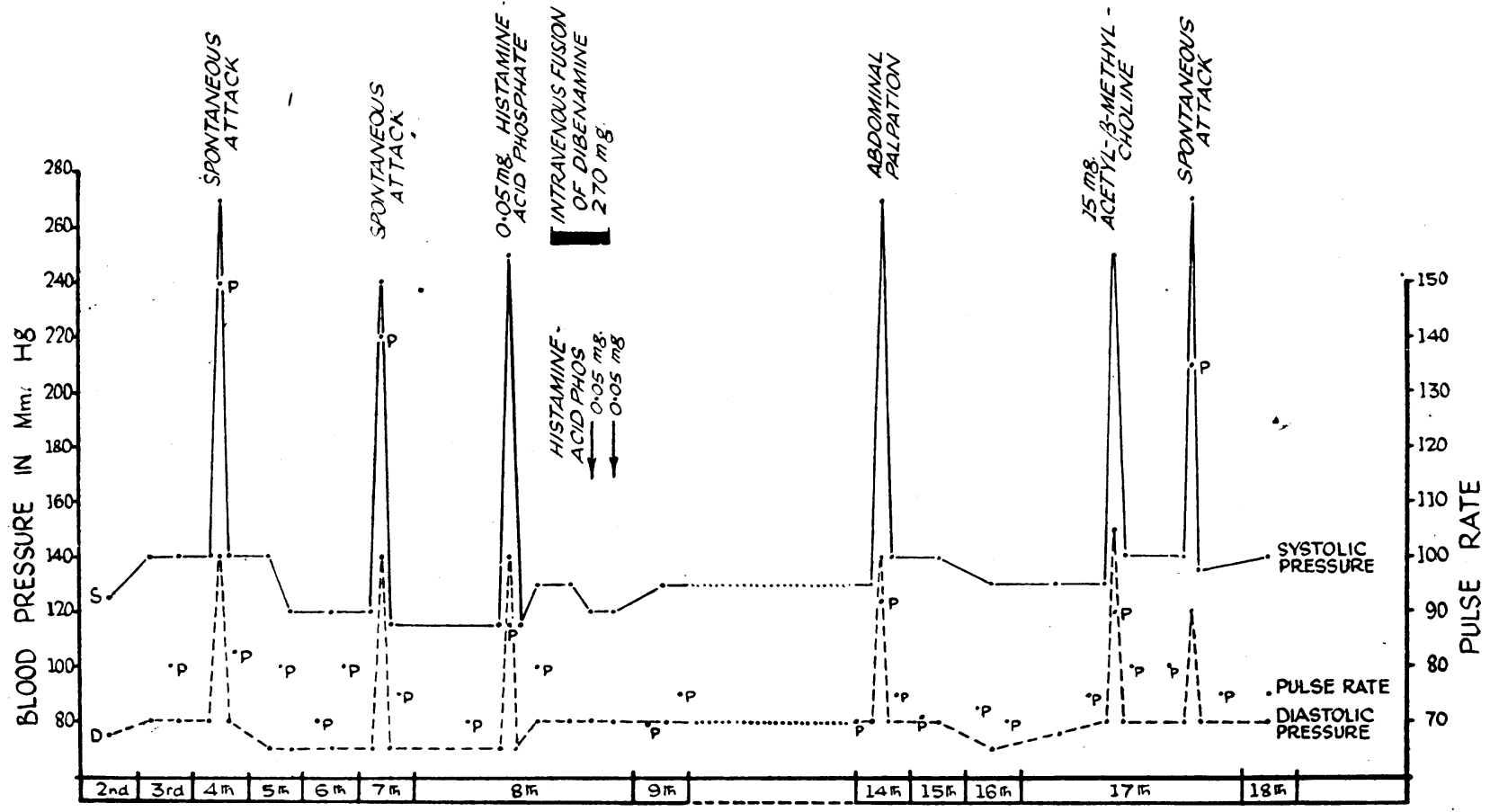

APRIL -

FIG. 1.-Blood-pressure readings and pulse rates before operation. 


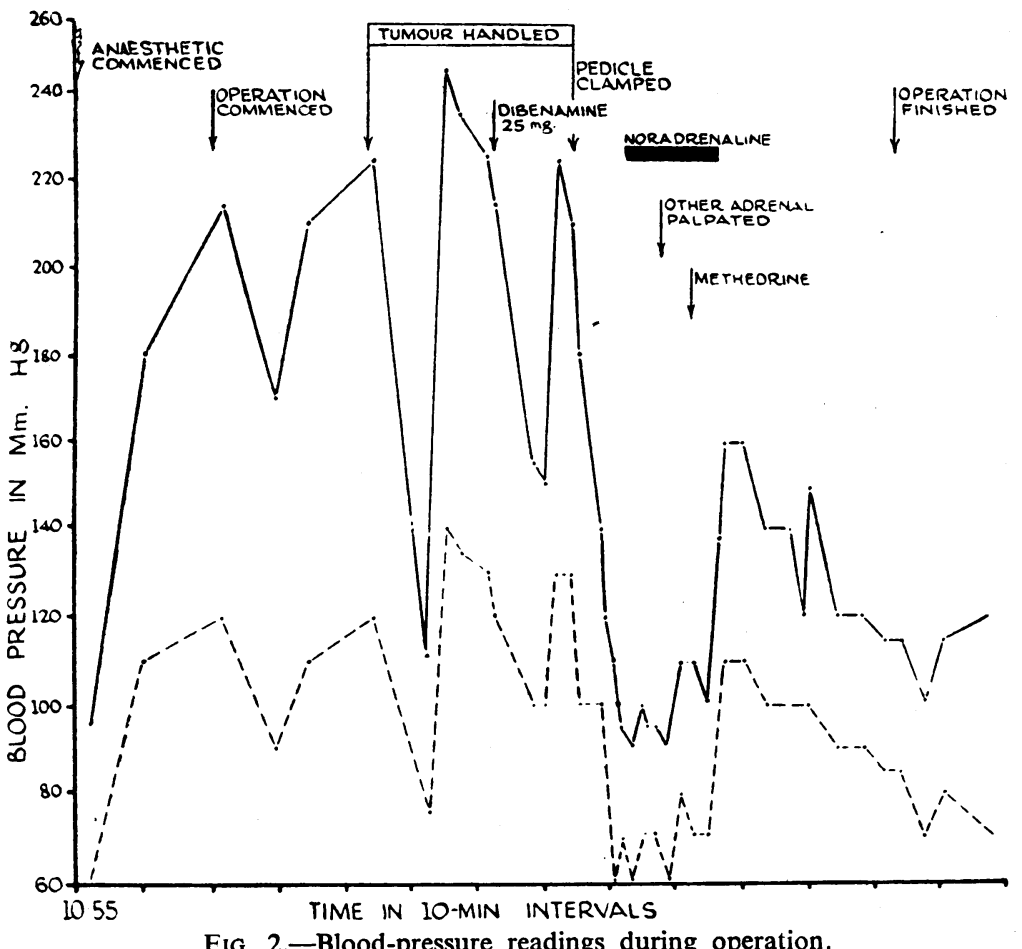

\section{Discussion}

Some features of the case require comment. The test substances, histamine (Roth and Kvale, 1945) and acetyl- $\beta$ methylcholine (Guarneri and Evans, 1948), failed to produce a typical paroxysm. The rise in blood pressure after injection of these substances and that following abdominal palpation were not associated with tachycardia, nor with any of the symptoms or other signs which characterize a spontaneously occurring attack. Symptomless paroxysmal rises in blood pressure have also been noted in patients with phaeochromocytoma (MacKeith, 1944).

The pressor effect of noradrenaline following intravenous injection is not associated with tachycardia or usually with distressing subjective symptoms (Swan, 1949). It might therefore be postulated that asymptomatic paroxysmal hypertension in the presence of a phaeochromocytoma is due to the release of noradrenaline, and that attacks with tachycardia and marked subjective symptoms follow the release of adrenaline. If this is so, the absence of hyperglycaemia during a spontaneous attack in this case is difficult to explain, since adrenaline is eight times more potent than noradrenaline in producing hyperglycaemia (West, 1947).

The dangers of operative removal are, first, the development of a fatal hypertensive paroxysm when the tumour is handled (Holst, 1938), and, secondly, the development of post-operative hypotension, which occurred in approximately half the reported cases. It has been suggested that noradrenaline rather than adrenaline should be used in its treatment (Walton, 1950), and its efficacy in our case is worthy of note, particularly since administration of the more commonly used pressor substances to an elderly patient with cardiac enlargement might carry considerable risk.

\section{Summary}

The successful removal of a phaeochromocytoma from an elderly woman is reported.

Certain unusual features of the case are briefly discussed, and the value of noradrenaline in the control of postoperative hypotension is noted.

The patient was under the care of Professor F. M. B. Allen, to whom we are indebted for co-operation and advice. We are indebted to Professor J. H. Biggart for the pathological study, and to Dr. T. B. B. Crawford, Edinburgh University, for the assay of the pressor activity of the tumour. The noradrenaline used was part of a gift to Professor Greenfield from Messrs. Bayer Products, Ltd.

\section{REFERENCES}

Guarneri, V., and Evans, J. A. (1948). Amer. J. Med., 4, 806 Hatch, F. N., Richards, V., and Spiegl, R. J. (1949). Ibid., 6. 633.

Holst, E. J. (1938). Acta med. scand., 94, 510.

MacKeith, R. (1944). Brit. Heart J., 6, 1.

Roth, G. M., and Kvale, W. F. (1945). Amer. J. med. Sci., 210, 653.

Shipley, A. M. (1929). Ann. Surg., 90, 742.

Swan, H. J. C. (1949). Lancet, 2, 508.

Walton, J. N. (1950). Ibid., 1, 438

West, G. B. (1947). J. Physiol., 106, 418. 